\title{
Plasma rico em plaquetas no tratamento de lesões condrais articulares induzidas experimentalmente em equinos: avaliação clínica, macroscópica, histológica e histoquímica
}

[Platelet-rich plasma in the treatment of articular chondral defects experimentally induced in horses: clinical, macroscopic, histopathological and histochemical evaluation]

\author{
A.L.M. Yamada ${ }^{1}$, A.M. Carvalho ${ }^{1}$, P.G.G. Oliveira ${ }^{1}$, S.L. Felisbino ${ }^{2}$, D.L. Queiroz ${ }^{3}$, \\ M.J. Watanabe ${ }^{4}$, C.A. Hussni ${ }^{4}$, A.L.G. Alves ${ }^{4}$ \\ ${ }^{1}$ Aluno de pós-graduação - Faculdade de Medicina Veterinária e Zootecnia - UNESP- Botucatu, SP \\ ${ }^{2}$ Instituto de Biociências - Universidade Estadual Paulista - UNESP- Botucatu, SP \\ ${ }^{3}$ Aluna de graduação - Faculdade de Medicina Veterinária e Zootecnia - UNESP- Botucatu, SP \\ ${ }^{4}$ Faculdade de Medicina Veterinária e Zootecnia, Universidade Estadual Paulista - UNESP- Botucatu, SP
}

\begin{abstract}
RESUMO
Estudou-se a eficácia do plasma rico em plaquetas (PRP) no tratamento de lesões condrais articulares, experimentalmente induzidas em equinos. Para isso, foi induzida uma lesão condral, na tróclea medial femoral dos dois membros pélvicos de quatro animais. Após 30 dias da indução, as oito articulações foram divididas em dois grupos. Os animais do grupo 1 receberam o tratamento intralesional e intra-articular com PRP, e os do grupo 2 foram tratados apenas com solução fisiológica. As avaliações clínicas, constituídas de exames de claudicação e análises do líquido sinovial, foram realizadas antes da indução da lesão - tempo zero -, quinzenalmente, até 120 dias e aos 150 dias. Avaliações macroscópicas, histológicas e histoquímicas foram realizadas no tempo zero e aos 150 dias. Os equinos do grupo 1 apresentaram melhora do grau de claudicação em relação aos do grupo 2. Os exames macroscópicos, histológicos e histoquímicos revelaram melhor tecido de reparação igualmente no grupo 1. Concluiu-se que a administração de PRP apresentou efeitos benéficos no tratamento de lesões condrais experimentais de equinos.
\end{abstract}

Palavras-chave: equino, articulação, artroscopia, plasma rico em plaquetas

\begin{abstract}
The use of platelet-rich plasma (PRP) in the treatment of articular cartilage defects induced experimentally in horses was studied. For this purpose, both patellofemoral joints of four animals were approached through arthroscopic surgery to perform a cartilage defect on the medial femoral trochlea. After 30 days of induction the eight joints were divided into two groups. Group 1 animals received intralesional and intra-articular treatment with PRP and Group 2 animals were treated only with saline solution. The clinical assessments, constituted by lameness signs and synovial fluid analysis, were performed before induction of injury (time zero) and every 15 days in 120 days, with last analysis on day 150. The macroscopic and morphologic analysis were performed at 0 and 150 days. During the experiment Group 1 animals showed improvement in lameness when compared to Group 2 animals. The macroscopic and morphological analysis showed a better tissue repair in the treated horses. Thus, the implantation of autologous PRP showed beneficial effects in the treatment of chondral lesions, experimentally induced in horses.
\end{abstract}

Keywords: horse, arthroscopy, joint, platelet rich plasma

\section{INTRODUÇÃO}

A osteoartrite é definida como uma desordem das articulações, considerada no grupo de distúrbios que resultam em um final comum:

Recebido em 1 de julho de 2011

Aceito em 10 de janeiro de 2012

E-mail: anamyamada@fmvz.unesp.br deterioração progressiva da cartilagem articular, acompanhada de alterações ósseas e de tecidos moles. Em estágios mais avançados, a osteoartrite é caracterizada por grande perda da integridade condral, o que ocasiona dor, deformações ósseas, esclerose subcondral, 
redução da mobilidade e da função articular. Em cavalos de esportes e na osteoartrite, a cartilagem articular é intensamente danificada (Schlueter e Orth, 2004; McIlwraith, 2005b). Na osteoartrite são encontrados diversos mediadores próinflamatórios catabólicos. Tais mediadores são determinantes no desenvolvimento da doença e compõem um importante método de avaliação do grau de implicação articular (Bertone et al., 2001; Sutton et al., 2009). As interleucinas são responsáveis pelo aumento de prostaglandinas no líquido sinovial. Estas causam a sensibilização de terminações sensoriais nervosas, aumento da dor e degradação da matriz extracelular da cartilagem articular (Schlueter e Orth, 2004).

A ausência de vasculatura, que resulta no não fornecimento para $o$ tecido de células progenitoras provenientes do sangue, e o lento mecanismo de turnover da cartilagem articular implicam mecanismos de reparação insatisfatórios, com formação exclusiva de tecido fibrocartilaginoso e manutenção da inflamação articular (Schlueter e Orth, 2004; McIlwraith, 2005b). Diversas técnicas cirúrgicas e terapias medicamentosas que recuperem a integridade estrutural e funcional da cartilagem hialina articular são pesquisadas, mas ainda sem o completo sucesso (Schlueter e Orth, 2004; McIlwraith, 2005b). O tratamento de lesões condrais com plasma rico em plaquetas (PRP) demonstra ser promissor; com resultados satisfatórios, representa uma alternativa terapêutica (Vinatier et al., 2009; Carmona et al., 2011).

O PRP é um biomaterial autólogo, rico em fatores de crescimento, com ação quimiotáxica, mitogênica, angiogênica, analgésica e antiinflamatória. Os fatores de crescimento liberados pelas plaquetas, concentradas no PRP, exercem grande influência no processo de reparação e cicatrização, sendo uma ferramenta de grande utilidade no auxílio ao tratamento de enfermidades ortopédicas (Maia, 2008; Carmona et al., 2011). A obtenção do PRP é relativamente simples e não onerosa. Consiste, basicamente, em centrifugações do sangue total. Diversos fatores de crescimento são capazes de acelerar e modular os processos de reparação, atuando na proliferação celular, diferenciação e formação de matriz extracelular (Carmona et al., 2009; Fortier et al., 2010). Acredita-se que o PRP seja, ainda, capaz de bloquear a expressão de fatores nucleares e a ação de moléculas próinflamatórias, como as interleucinas, atuando de forma anti-inflamatória e analgésica (ElSharkawy et al., 2007). A aplicação intralesional ou intra-articular do PRP reduz os sinais clínicos da osteoartrite, acelera a reparação e não apresenta nenhum tipo de efeito indesejável (Carmona et al., 2011).

O objetivo deste trabalho foi avaliar o efeito da aplicação do PRP sobre defeitos da cartilagem articular, produzidos experimentalmente na tróclea medial do fêmur, através de exames clínicos, laboratoriais e artroscópicos, destacando os benefícios e desafios encontrados no uso deste biocomposto no tratamento de lesões condro-articulares de equinos.

\section{MATERIAL E MÉTODOS}

A metodologia adotada durante o desenvolvimento do presente trabalho foi aprovada pela Câmara de Ética em Experimentação Animal da Faculdade de Medicina Veterinária e Zootecnia da Universidade Estadual Paulista, Botucatu, em 17 de dezembro de 2008, sob protocolo 256/2008.

Foram utilizados quatro equinos adultos, clinicamente hígidos, com três a quatro anos de idade, divididos em dois grupos (G). As articulações femoropatelares dos membros pélvicos direito e esquerdo dos animais foram abordadas por cirurgia artroscópica para a realização de um defeito condral e submetidas a tratamento conforme o grupo. Os animais do G1 receberam implante autólogo de PRP de forma intralesional e injeções intra-articulares. Os do $\mathrm{G} 2$ formaram o grupo-controle do experimento e foram tratados apenas com solução fisiológica, seguindo os mesmos procedimentos realizados para o G1.

O procedimento artroscópico para a indução das lesões condrais foi considerado como tempo (dia) zero do experimento (T-0). Foram estabelecidos dois portais, de acordo com a técnica descrita por McIlwraith (2005a). Pelo portal artroscópico primário, foi inserida a óptica para inspeção articular, e, pelo portal instrumental, foram realizados a lesão condral, o implante dos tratamentos e a coleta das amostras 
para os exames histopatológicos e histoquímicos. A lesão condral foi realizada na tróclea medial do fêmur, o mais proximal possível e evitando o sulco intertroclear, criada com o auxílio de brocas motorizadas, com desgaste suficiente para obter a dimensão da lesão condral desejada. As lesões foram induzidas apenas retirando totalmente a cartilagem hialina, não havendo abrasão, perfuração ou sangramento do osso subcondral, e apresentavam $1 \mathrm{~cm}$ de diâmetro.

O PRP foi processado conforme Vendramin et al. (2006). Foram coletados $80 \mathrm{~mL}$ de sangue dos dois equinos de G1 pela venopunção jugular, acondicionados em tubos com citrato de sódio a $3,8 \%$ e submetidos a duas centrifugações seriadas com crescente velocidade de rotação. Para tal, a contagem do PRP deve ser igual ou maior que 300.000 plaquetas $/ \mu \mathrm{L}$ para a viabilidade de utilização, obtida pela contagem microscópica - em câmara de Neubauer espelhada. $\mathrm{O}$ procedimento artroscópico para o tratamento intralesional foi realizado 30 dias após (T-30) a indução das lesões em T-0 (dia zero). Em T-30, no G1, os tratamentos foram realizados com o PRP em forma de gel, permitindo a fixação do tratamento no leito receptor. Para isso, no momento da aplicação, foram adicionados ao PRP 5\% de cloreto de cálcio (Calcium Chloride Solution, Sigma Aldrich, Sigma Life Science, Brasil) a $10 \%$ e 5\% de trombina bovina (Thrombin from bovine plasma, lyophilized powder, 600-2,000 NIH units/mg protein (biuret) - Aldrich, Sigma Life Science, Brasil) para formação do gel de fibrina e ativação plaquetária. A articulação em T-30 foi insuflada com gás carbônico ao invés de fluido estéril, permitindo, assim, o implante do gel. As outras aplicações de PRP foram realizadas por meio de injeções intra-articulares, na articulação femoropatelar, entre o ligamento patelar médio e patelar medial, com uma seringa descartável portando $10 \mathrm{~mL}$ de plasma rico em plaquetas para cada articulação, em forma líquida, sem a adição de trombina. As aplicações intra-articulares foram realizadas a cada 15 dias após T-30, em um total de três aplicações (T-45, T-60 e T-75).

A coleta do líquido sinovial para as análises foi realizada em T-0, a cada 15 dias até 90 dias (T-15, T-30, T-45, T-60, T-75, T-90), em 120 e 150 dias (T-120 e T-150) para os dois grupos. O líquido sinovial foi coletado da articulação femoropatelar, entre o ligamento patelar médio e o patelar medial, depositado em frascos com EDTA e sem EDTA para todas as análises realizadas. A análise do líquido sinovial foi dividida em quatro categorias: exame físico, exame químico, exame citológico e quantificação de prostaglandina $\mathrm{E}_{2}\left(\mathrm{PGE}_{2}\right)$. No exame físico, o aspecto e a viscosidade do líquido sinovial foram avaliados no momento da coleta. No exame químico, foram avaliadas, com fitas reagentes de teste rápido (Combur 10 Test $\mathrm{M}$, Cobas, Roche, Brasil), a quantidade de proteína e a glicose. Ainda no exame químico, o fibrinogênio foi dosado pelo método de Jain (1993). No exame citológico, foi efetuada a contagem global e diferencial de células nucleadas. Os leucócitos foram quantificados em porcentagens.

A determinação da concentração da prostaglandina $\mathrm{E}_{2}\left(\mathrm{PGE}_{2}\right)$ sinovial foi realizada por meio de teste imunoenzimático utilizando-se um kit ELISA (Enzyme Linked Immunosorbent Assay) comercial (Kit Parameter ${ }^{\mathrm{TM}} \mathrm{PGE}_{2}, \mathrm{PGE}_{2}$ Assay. R\&D Systems, Inc. Minneapolis, EUA. Distribuído por LGC Biotecnologia, São Paulo, Brasil), de acordo com as instruções observadas na bula do produto. A absorbância foi lida em comprimentos de 450nm, em leitor de microplaca ELISA, e foi correlacionada a um padrão com variação de 18 a $2500 \mathrm{pg} / \mathrm{mL}$. As amostras que se apresentaram fora dessa faixa de resultados foram reanalisadas após nova diluição. A curva de regressão da análise e a conversão das densidades ópticas obtidas na leitura foram realizadas com o auxílio de um software (Instat Graph Pad Instat).

Os grupos foram avaliados clinicamente, imediatamente antes da realização do defeito de cartilagem por artroscopia (T-0) e em T-15, T30, T-45, T-60, T-75, T-90, T-120 e T-150, quanto à claudicação, graduada em escores de 0 a 5, segundo Stashak (2006). Foram realizados testes de flexão forçada na articulação femorotibiopatelar nos dois grupos. Havendo exacerbação da claudicação após a flexão, era realizada uma nova graduação do escore. No procedimento artroscópico de T-0 e T-150 do experimento, os dois grupos foram abordados para a avaliação macroscópica da cartilagem articular. Em T-150, na região onde foi realizada a lesão condral, foram avaliadas as superfícies articulares (cartilagem) da tróclea medial do fêmur, quanto ao aspecto geral da superfície cartilaginosa, aspecto do tecido cicatricial, além 
da palpação local indireta com um obturador rombo, verificando-se a consistência do tecido neoformado. Nesses mesmos momentos, foram realizadas as coletas de amostras para as análises histopatológicas e histoquímicas.

Para a realização das análises histológica e histoquímica, os cortes foram processados pelas técnicas habituais de desparafinização e corados pelos métodos de hematoxilina-eosina, picrosirius red e azul de toluidina. A análise das lâminas foi realizada por microscopia óptica e em microscópio de polarização para as lâminas coradas com picrosirius, sem o prévio conhecimento dos grupos a que pertenciam cada lâmina. Para a avaliação das alterações histológicas e histoquímicas da reparação da cartilagem lesada, foram considerados os seguintes aspectos: predominância de condrócitos, organização celular e tecidual da cartilagem, qualidade da matriz extracelular, presença de fibrilas colágenas e fibrose (Wilke et al., 2007).

As análises estatísticas foram realizadas separadamente, comparando-se os grupos dentro de cada tempo e os tempos dentro de cada grupo. Para as aferições numéricas - contagem de células nucleadas, contagem relativa de mononucleares, linfócitos e neutrófilos - , foram realizados, de forma separada, a análise de variância de tratamentos com medidas repetidas no tempo e o teste Tukey para comparação de médias, sendo que as médias foram inseridas nas tabelas, e os valores de $P$ nas legendas. Para aferição em escores - proteína, fibrinogênio e claudicação -, foi usado o teste não paramétrico Kruskal-Wallis, comparando-se individualmente os tratamentos em cada tempo e separadamente, e os tempos dentro de cada tratamento. Quando houve diferença estatística significativa $(\mathrm{P}<0,05)$, foi usado o teste Tukey para comparação das medianas, sendo os valores de $P$, neste caso, inseridos nas tabelas.

\section{RESULTADOS E DISCUSSÃO}

Nesse estudo, não foi adotada a lesão do osso subcondral, sendo apenas exposta a sua superfície. A perfuração ou abrasão do osso subcondral induz a migração de células e dos fatores de crescimento provenientes da vasculatura subcondral e da medula óssea para o local da lesão; além disso, facilita a adesão do coágulo de fibrina (Vinatier et al., 2009; Fortier et al., 2010). Sendo assim, a perfuração do osso subcondral neste estudo iria, de forma significativa, interferir na avaliação dos efeitos do tratamento proposto, sendo, portanto, invariavelmente evitada.

A média de plaquetas quantificadas no PRP foi de 362.350plaquetas $/ \mu \mathrm{L}$, o que representou uma taxa de enriquecimento plaquetário médio de $106,5 \%$ ou um aumento de duas vezes a concentração de plaquetas do sangue total para o PRP. Concentrações acima de 500.000 plaquetas $/ \mu \mathrm{L}$ ou enriquecimento três vezes superior aos valores plaquetários basais, como recomenda parte da literatura (Marx et al., 1998; Maia, 2008) não foram alcançados. A utilização do PRP durante o experimento foi viabilizada, já que concentrações maiores ou iguais a 300.000 plaquetas $/ \mu \mathrm{L}$ são adequadas para equinos, expressando uma concentração suficiente de fatores de crescimento e sendo eficazes quando utilizadas em diferentes terapias (Foster et al., 2009; McCarrel e Fortier, 2009; Carmona et al., 2011).

A aplicação intralesional dos tratamentos em T30 foi realizada com o auxílio de agulha modelo Komiyashiki 11G. Essa agulha permitiu a adequada aplicação do composto em fase final de gelificação. Desse modo, não foram observadas obstruções da agulha pelo tratamento já gelificado ou aplicação exacerbada do implante fora do local da lesão; além disso, esse modelo de agulha possui, sem o trocater, a ponta romba e não ocasionou danos adicionais na cartilagem articular. A distensão articular com gás carbônico permitiu, de forma satisfatória, a fixação do gel no leito receptor.

A utilização de $5 \%$ de cloreto de cálcio a $10 \%$ e a de um ativador de fibrina igualmente a $5 \%$ na amostra previamente separada para o tratamento foram suficientes para a formação e adesão do gel de fibrina. A adição de trombina ao PRP resultou na polimerização do fibrinogênio em fibrina, que é uma proteína adesiva (Roussy et al., 2007). O cloreto de cálcio demonstrou ser um fraco ativador plaquetário. Sua principal função é antagonizar o anticoagulante utilizado, permitindo a formação do gel. Já a trombina é um potente ativador, degranulando a maior parte dos grânulos intraplaquetários, que liberam todo 
o seu conteúdo (Everts, 2006). O gel de PRP, formado a partir da adição de trombina, tem sido utilizado com arcabouço tridimensional em tratamentos de lesões da cartilagem articular. A facilidade de aplicação, a polimerização e a elevada aderência no local da lesão são vantagens apresentadas na utilização desse gel. Além disso, o gel reúne uma variedade de fatores de crescimento, que favoreceram a diferenciação condrogênica (Wilke et al., 2007).

Os benefícios da aplicação intralesional e intraarticular de PRP refletiram-se na redução dos sinais clínicos associados à osteoartrite. Os equinos do G1 apresentaram escores de claudicação mais baixos quando comparados aos do G2 (Tab. 1), mesmo após a flexão forçada
$(\mathrm{P}<0,05)$. Ambos os grupos apresentaram aumento da claudicação após a flexão forçada. Carmona et al. (2009) observaram melhora no grau de claudicação em animais portadores de artropatias após a terceira aplicação intraarticular de PRP. Ainda segundo o estudo citado anteriormente, os animais do G1 apresentaram melhora evidente de claudicação após a segunda aplicação de PRP intra-articular, realizada em T45, T-60 e T-75. Injeções intra-articulares de plasma rico em plaquetas são comprovadamente benéficas e eficazes na redução da claudicação em equinos (Carmona et al., 2009; LopezVidriero et al., 2010; Carmona et al., 2011). Não foram observadas reações clínicas indesejáveis em nenhum dos grupos.

Tabela 1. Mediana dos escores de claudicação e valores de $\mathrm{P}$ do grupo 1 e do grupo 2 nos tempos do experimento

\begin{tabular}{|c|c|c|c|c|c|c|c|c|c|c|}
\hline \multirow{2}{*}{ Grupo } & \multicolumn{9}{|c|}{ Tempo (Dias) } & \multirow{2}{*}{$P$} \\
\hline & 0 & 15 & 30 & 45 & 60 & 75 & 90 & 120 & 150 & \\
\hline \multirow{2}{*}{ G1 } & $0,0 \pm 0$ & $0,5 \pm 0,5$ & $0,5 \pm 05$ & $2,0 \pm 0$ & $1,0 \pm 0$ & $0,0 \pm 0$ & $0,0 \pm 0$ & $0,0 \pm 0$ & $0,0 \pm 0$ & \multirow[b]{2}{*}{$<0,001$} \\
\hline & $\mathrm{Aa}$ & $\mathrm{Aa}$ & $\mathrm{Aa}$ & $\mathrm{Aa}$ & $\mathrm{Aa}$ & $\mathrm{Ab}$ & $\mathrm{Ab}$ & $\mathrm{Ab}$ & $\mathrm{Ab}$ & \\
\hline \multirow{2}{*}{ G2 } & $0,0 \pm 0$ & $1,0 \pm 0$ & $1,0 \pm 0,5$ & $1,5 \pm 0,9$ & $2,0 \pm 0$ & $2,0 \pm 0$ & $2,0 \pm 0$ & $1,0 \pm 0$ & $0,5 \pm 0,5$ & \multirow{2}{*}{$<0,001$} \\
\hline & $\mathrm{Ba}$ & $\mathrm{ABa}$ & $\mathrm{ABa}$ & $\mathrm{ABa}$ & $\mathrm{Aa}$ & Aa & $\mathrm{Aa}$ & $\mathrm{ABab}$ & $\mathrm{ABab}$ & \\
\hline$P$ & 1,000 & 0,565 & 0,019 & 0,094 & 0,002 & 0,002 & 0,006 & 0,007 & 0,023 & \\
\hline
\end{tabular}

Teste não paramétrico de Kruskal-Wallis. *Medianas seguidas por letras distintas minúsculas na coluna e maiúsculas na linha diferem entre si pelo teste Tukey $(\mathrm{P}<0,05)$.

Resumo descritivo das medianas seguidas pelo desvio padrão.

No exame do líquido sinovial, o aspecto e a concentração de glicose não apresentaram diferenças significativas entre os grupos e momentos analisados, variando dentro dos padrões normais para a espécie. Houve decréscimo da viscosidade apenas após os procedimentos artroscópicos, em T-15 e T-45. Para a proteína e o fibrinogênio, quando foram comparados os tratamentos em cada tempo, não se observou diferença significativa $(\mathrm{P}>0,05)$. As concentrações de proteína e fibrinogênio foram elevadas apenas após as cirurgias, variando entre os momentos analisados. A sinovite decorrente das artroscopias resulta em efusão de líquido sinovial, influxo de proteínas, fibrinogênio e leucócitos (Stashak, 2006), explicando essa alteração.

No exame citológico do líquido sinovial, as maiores médias da contagem global de células nucleadas foram observadas nos momentos T-15 e T-45 para os dois grupos. Na quantificação relativa de células mononucleares, houve diferença estatística entre os tratamentos realizados $(\mathrm{P}=0,008)$, e entre os tempos analisados $(\mathrm{P}<0,001)$ (Tab. 2). Nos animais do G2, a contagem relativa de células mononucleares foi menor que a dos equinos do G1 $(\mathrm{P}<0,001)$. O líquido sinovial normal deve apresentar grande quantidade de células mononucleares $(>80 \%)$ derivadas de monócitos sanguíneos, sinoviócitos e macrófagos teciduais. O decréscimo da contagem de células mononucleares pode representar graus variados de sinovite e osteoartrite (Stell, 2008; Pozzobon et al., 2009), o que provavelmente ocorreu com o grupo-controle. Em T-45, o G1 apresentou um aumento significativo da porcentagem de linfócitos (Tab. 3), o que pode ter sido resultante de reação adversa à trombina, ao cloreto de cálcio ou, menos provável, ao próprio PRP. A porcentagem de neutrófilos pode predizer a magnitude da inflamação (Stell, 2008; Pozzobon et al., 2009). Neste estudo, os animais do G2 apresentaram porcentagens discretamente mais elevadas de neutrófilos quando comparados aos do G1 (Tab. 4), refletindo maior inflamação articular. Os do G1 apresentaram resultados sutilmente melhores nas análises do líquido sinovial. O PRP, apesar de possuir efeito antiinflamatório, também ativa citocinas, aumenta a 
permeabilidade vascular e realiza quimiotaxia sobre monócitos, (El-Sharkawy et al., 2007; Vinatier et al., 2009), podendo explicar os valores relativos variados encontrados na análise do líquido sinovial nos equinos do G1.
Nos do G2, observou-se maior inflamação articular, comprovada pela redução de células mononucleares e pelo maior valor relativo de neutrófilos.

Tabela 2. Média relativa de células mononucleares, em porcentagem, no líquido sinovial do grupo 1 e do grupo 2 em todos os tempos do experimento

\begin{tabular}{|c|c|c|c|c|c|c|c|c|c|c|}
\hline \multirow{2}{*}{ Grupo } & \multicolumn{9}{|c|}{ Tempo (Dias) } & \multirow{2}{*}{ Média } \\
\hline & 0 & 15 & 30 & 45 & 60 & 75 & 90 & 120 & 150 & \\
\hline \multirow{2}{*}{ G1 } & 91,2 & 91,2 & 93,5 & 53,8 & 83,5 & 46,8 & 76,2 & 84,0 & 45,5 & \multirow{2}{*}{$73,9 \mathrm{a}$} \\
\hline & $\pm 6,2$ & $\pm 4,7$ & $\pm 1,7$ & $\pm 35,4$ & $\pm 3,3$ & $\pm 53,9$ & $\pm 21,3$ & $\pm 12,1$ & $\pm 52,1$ & \\
\hline \multirow{2}{*}{ G2 } & 78,0 & 66,5 & 59,2 & 64,0 & 81,0 & 58,8 & 54,5 & 46,8 & 21,8 & \multirow{2}{*}{$58,9 \mathrm{~b}$} \\
\hline & $\pm 8,0$ & $\pm 7,5$ & $\pm 39,8$ & $\pm 43,0$ & $\pm 15,0$ & $\pm 29,8$ & $\pm 44,2$ & $\pm 37,4$ & $\pm 31,1$ & \\
\hline Média & $87,9 \mathrm{~A}$ & $82,4 \mathrm{AB}$ & $84,8 \mathrm{~A}$ & $68,4 \mathrm{AB}$ & $78,5 \mathrm{AB}$ & $52,1 \mathrm{~B}$ & $57,4 \mathrm{AB}$ & $70,8 \mathrm{AB}$ & $53,8 \mathrm{~B}$ & \\
\hline
\end{tabular}

Análise de variância entre os tratamentos com medidas repetidas no tempo.

Médias seguidas por letras distintas minúsculas na coluna e maiúsculas na linha diferem entre si pelo teste Tukey $(\mathrm{P}<0,05)$. Resumo descritivo das médias seguidas pelo desvio-padrão.

$\mathrm{P}$ tratamento $=0,008 ; \mathrm{P}$ tempo $<0,001 ; \mathrm{P}$ interação tratamento $\mathrm{x}$ tempo $=0,163$.

Tabela 3. Média relativa de linfócitos, em porcentagem, no líquido sinovial do grupo 1 e do grupo 2 em todos os tempos do experimento

\begin{tabular}{|c|c|c|c|c|c|c|c|c|c|c|}
\hline \multirow{2}{*}{ Grupo } & \multicolumn{9}{|c|}{ Tempo (Dias) } & \multirow{2}{*}{ Média } \\
\hline & 0 & 15 & 30 & 45 & 60 & 75 & 90 & 120 & 150 & \\
\hline \multirow{2}{*}{ G1 } & 7,0 & 6,2 & 6,5 & 45,8 & 13,5 & 2,2 & 23,0 & 13,5 & 3,2 & \multirow[b]{2}{*}{13,4} \\
\hline & $\pm 2,5 \mathrm{Ba}$ & $\pm 2,5 \mathrm{Ba}$ & $\pm 1,7 \mathrm{Ba}$ & $\pm 35,7 \mathrm{Aa}$ & $\pm 2,5 \mathrm{Ba}$ & $\pm 2,8 \mathrm{Bb}$ & $\pm 20,4 \mathrm{Aab}$ & $\pm 14,5 \mathrm{Ba}$ & $\pm 4,7 \mathrm{Ba}$ & \\
\hline \multirow{2}{*}{ G2 } & 14,2 & 19,5 & 10,8 & 8,5 & 16,0 & 30,8 & 3,5 & 17,2 & 27,0 & \multirow{2}{*}{16,4} \\
\hline & $\pm 3,7 \mathrm{Aa}$ & $\pm 6,4 \mathrm{Aa}$ & $\pm 7,5 \mathrm{Aa}$ & $\pm 5,6 \mathrm{Ab}$ & $\pm 13,8 \mathrm{Aa}$ & $\pm 31,4 \mathrm{Aa}$ & $\pm 2,3 \mathrm{Ab}$ & $\pm 16,2 \mathrm{Aa}$ & $\pm 37,2 \mathrm{Aa}$ & \\
\hline Média & 8,2 & 10,6 & 7,6 & 16,8 & 10,9 & 13,1 & 21,7 & 18,8 & 12,7 & \\
\hline
\end{tabular}

Análise de variância entre os tratamentos com medidas repetidas no tempo.

Médias seguidas por letras distintas minúsculas na coluna e maiúsculas na linha diferem entre si pelo teste Tukey $(\mathrm{P}<0,05)$. Resumo descritivo das médias seguidas pelo desvio-padrão.

$\mathrm{P}$ tratamento $=0,070 ; \mathrm{P}$ tempo $=0,073 ; \mathrm{P}$ interação tratamento $\mathrm{x}$ tempo $=0,003$

Tabela 4. Média relativa de neutrófilos, em porcentagem, no líquido sinovial do grupo 1 e do grupo 2 em todos os tempos do experimento

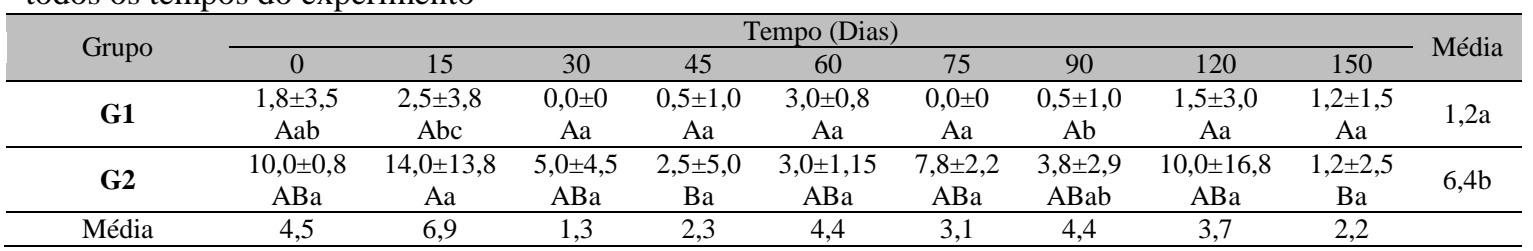

Análise de variância entre os tratamentos com medidas repetidas no tempo.

Médias seguidas por letras distintas minúsculas na coluna e maiúsculas na linha diferem entre si pelo teste Tukey $(\mathrm{P}<0,05)$. Resumo descritivo das médias seguidas pelo desvio-padrão.

$\mathrm{P}$ tratamento<0,001; $\mathrm{P}$ tempo $=0,106 ; \mathrm{P}$ interação tratamento $\mathrm{x}$ tempo $=0,049$.

$\mathrm{Na}$ quantificação de prostaglandina, houve diferença estatística entre os grupos e entre os tempos de análise durante o experimento $(\mathrm{P}<0,001)$ (Tab. 5). No G2, os valores foram mais baixos, no de $\mathrm{PGE}_{2}$ foram mais baixos, e no G1 mais altos. Houve um padrão de acréscimo da concentração de $\mathrm{PGE}_{2}$ em T-15 e T-45. O resultado observado para a concentração de prostaglandina confronta-se com os achados dos exames clínicos, em que os animais do G1 apresentaram o menor grau de claudicação. Tal fato pode ser explicado em conceitos descritos por De Grauw et al. (2006). Esses autores observaram que articulações acometidas por diversas doenças articulares, apresentando concentrações elevadas de $\mathrm{PGE}_{2}$ não apresentavam, necessariamente, melhora do grau de claudicação após a anestesia intraarticular, sugerindo que a $\mathrm{PGE}_{2}$ poderia não estar relacionada com o grau de claudicação. Além 
disso, apesar do efeito anti-inflamatório do PRP, plaquetas degranuladas em lesões tissulares também são capazes de ativar alguns tipos de citocinas, alterando a composição e homeostasia do líquido sinovial (El-Sharkawy et al., 2007; Vinatier et al., 2009), o que também poderia explicar valores mais altos de $\mathrm{PGE}_{2}$

Tabela 5. Média da concentração de $\mathrm{PGE}_{2}$ no líquido sinovial do grupo 1 e do grupo 2 em todos os momentos do experimento

\begin{tabular}{ccccccccccc}
\hline \multirow{2}{*}{ Grupo } & \multicolumn{7}{c}{ Tempo (Dias) } & \multicolumn{1}{c}{ Média } \\
\cline { 2 - 10 } & 0 & 15 & 30 & 45 & 60 & 75 & 90 & 120 & 150 \\
\hline G1 & 508,3 & 764,0 & 630,2 & 1411,1 & 1070,2 & 1277,2 & 2076,5 & 1419,2 & 1382,7 & $1171,0 \mathrm{a}$ \\
G2 & 395,2 & 498,6 & 476,0 & 1472,7 & 1597,7 & 725,3 & 855,2 & 1405,9 & 870,9 & $921,9 \mathrm{~b}$ \\
Média & $489,9 \mathrm{C}$ & $583,2 \mathrm{BC}$ & $502,2 \mathrm{C}$ & $1284,4 \mathrm{~A}$ & $1302,1 \mathrm{~A}$ & $1019,5 \mathrm{ABC}$ & $1600,5 \mathrm{~A}$ & $1175,6 \mathrm{AB}$ & $1125,9 \mathrm{AB}$ & \\
\hline
\end{tabular}

Análise de variância entre os tratamentos com medidas repetidas no tempo.

Médias seguidas por letras distintas minúsculas na coluna e maiúsculas na linha diferem entre si pelo teste Tukey $(\mathrm{P}<0,05)$. Resumo descritivo das médias seguidas pelo desvio-padrão.

Valores em picogramas por mililitro. Resumo descritivo das médias.

$\mathrm{P}$ tratamento=0,013; $\mathrm{P}$ tempo<0,001; $\mathrm{P}$ interação tratamento $\mathrm{x}$ tempo $=0,127$.

No $150^{\circ}$ dia após a indução das lesões, foram observadas sinovite e irregularidades ao redor da lesão, principalmente nos equinos do G2. Nos do G1, observou-se melhor tecido cicatricial macroscópico quando comparado aos do G2 (Fig. 1). Os resultados apresentados na inspeção macroscópica das lesões tratadas corroboram com dados encontrados na literatura, em que pesquisas que utilizaram o PRP no tratamento de lesões condrais induzidas ou de ocorrência natural demonstraram a formação de um tecido cicatricial branco, liso, aparentemente fibroso e bem aderido, preenchendo completamente as falhas de cartilagem. As lesões condrais que não foram submetidas a esses tratamentos apresentaram falha do preenchimento e manutenção da degradação da cartilagem articular (Wilke et al., 2007; McIlwraith et al., 2010; Raheja et al., 2011).

Os dois grupos apresentaram formação de fibrocartilagem, com diferentes intensidades de fibrose cicatricial e feixes de fibras colágenas desorganizadas no local onde foi induzida a lesão (Fig. 2). Houve perda de celularidade, desorganização da matriz interterritorial e da disposição celular. Os equinos do G2 apresentaram, predominantemente, células fibroblastóides, e pôde ser observada melhor organização tecidual e maior número aparente de condrócitos nos tecidos cicatriciais nos animais do G1. Nos cortes corados com picrosirius red foi confirmada a presença de grande quantidade de fibrose nos dois grupos. Porém, nas imagens polarizadas nos animais do G1, pôde-se observar predominância de fibrose em fase inicial, com preponderância de colágeno tipo II (verde). Os animais do G2 apresentaram feixes de fibras mais espessas e predominância de colágeno tipo I (amarelo).

Nos cortes corados com azul de toluidina, os equinos do G1 apresentaram marcação moderada e irregular, enquanto os cortes nos do G2 não se coraram pelo azul de toluidina. Essa resposta ao tratamento pode ser decorrente da capacidade do PRP em reduzir a resposta inflamatória e inibir enzimas catabólicas, favorecendo a organização do colágeno, a migração e a proliferação celular (Carter et al., 2003). A presença de fatores de crescimento em abundância no PRP também estimula a produção de proteoglicanos pelos condrócitos e acelera a reparação tecidual (Gaissmaier et al., 2008), o que esclarece a melhora no aspecto histoquímico dos cortes corados com azul de toluidina no G1. A melhora morfológica nos animais do G1 foi resultante dos efeitos mitogênico, quimiotáxico e proliferativo do PRP, já citados por Fortier et al. (2010) e Milano et al. (2010). 


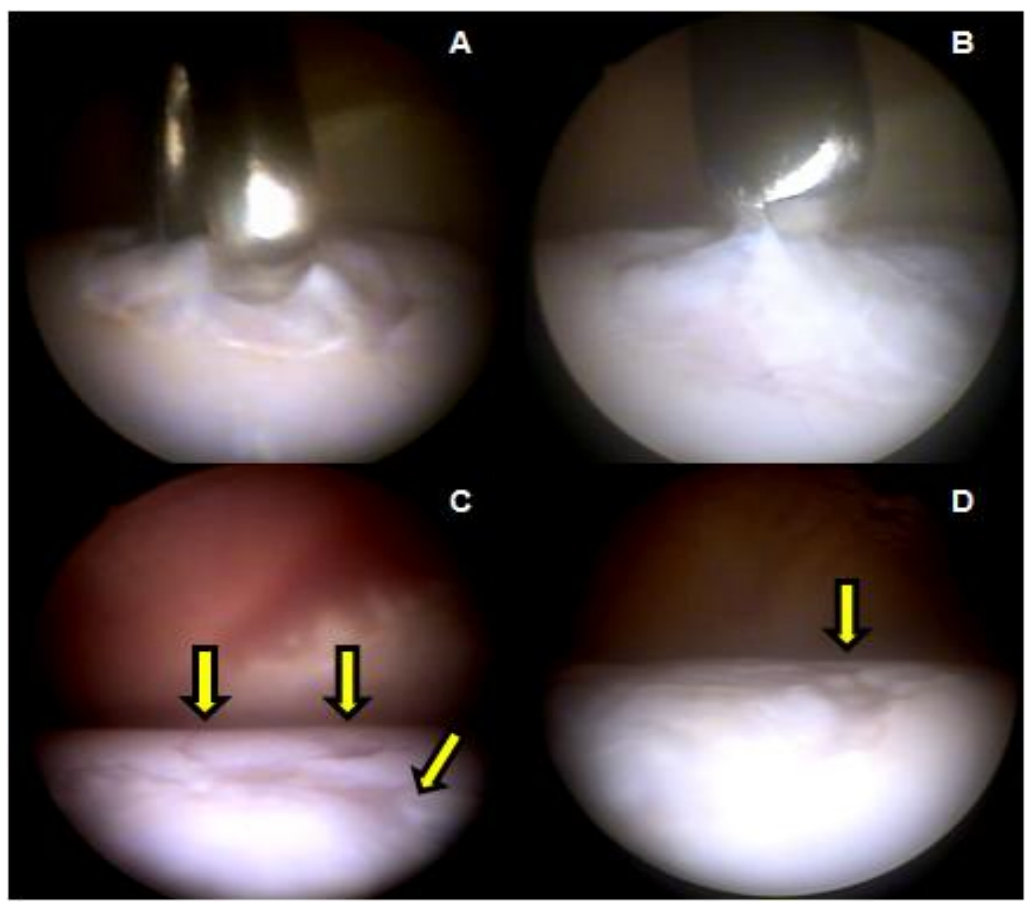

Figura 1. Imagens artroscópica das articulações em T-150. Palpação e exame com a probe do tecido cicatricial preenchendo completamente a lesão no G1 (A). Remoção do tecido neoformado para a biópsia com auxílio de pinça tipo Ferris-Smith. O tecido cicatricial está bem aderido às bordas da lesão no G1 (B). Falhas de preenchimento (setas), irregularidades (setas), fibrilações, pouca formação de tecido cicatricial e manutenção da degradação articular no G2 (C e D).

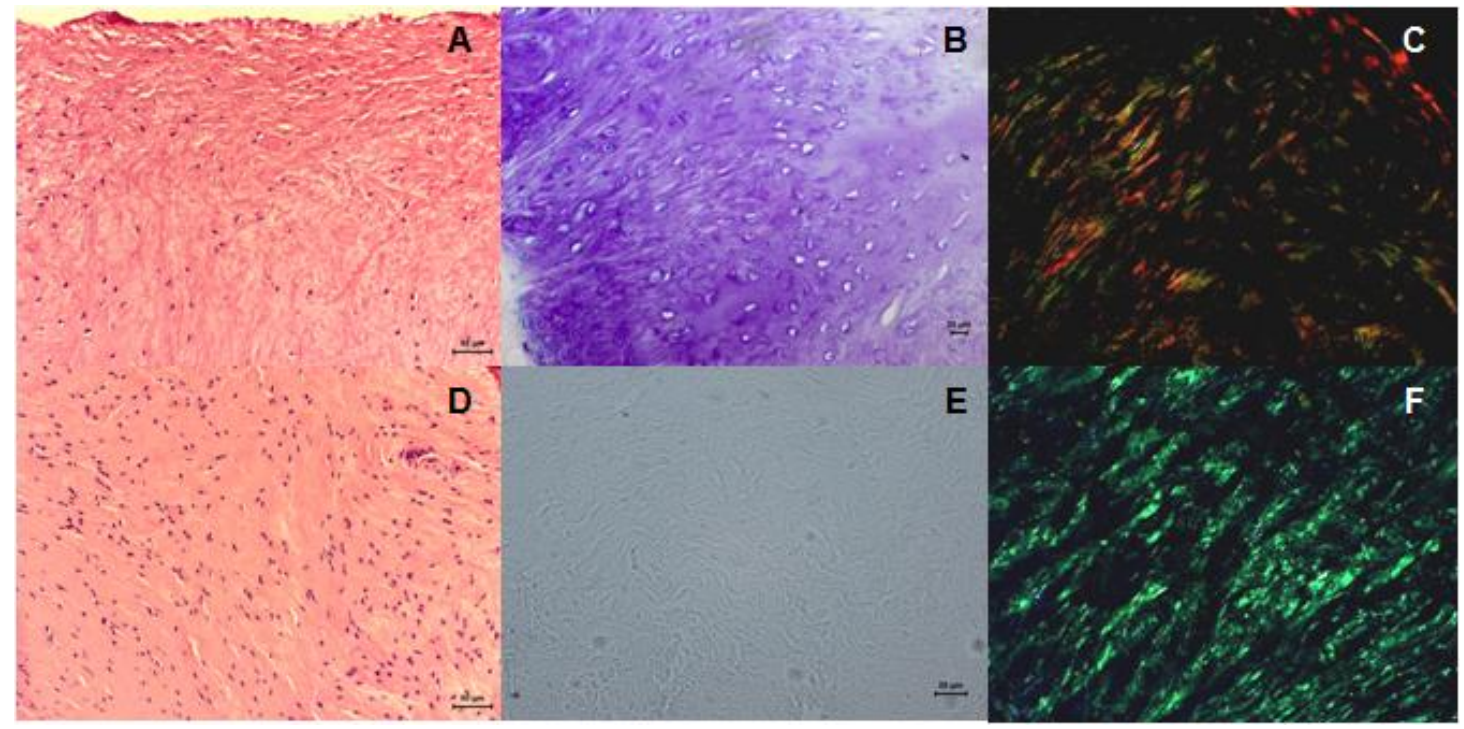

Figura 2. Fotomicroscopia de luz de G1 (A) e G2(D); H\&E. Formação de tecido fibrocartilaginoso, porém com maior predominância de condrócitos no G1. Fotomicroscopia de luz de G1 (B) e G2(E); azul de toluidina. Marcação irregular em G1 e nenhuma marcação em G2. Fotomicroscopia de luz polarizada de G1 (C) e G2(F); picrosírius red. O G2 apresenta fibras espessas e predominância da cor amarela ou vermelha (colágeno tipo I). O G1 apresenta fibras mais finas e predominância da cor verde (colágeno tipo II). Objetivas 20x. 


\section{CONCLUSÕES}

O tratamento das lesões experimentais com PRP melhora o aspecto macroscópico do tecido de reparação. O PRP reduziu os escores de claudicação dos animais tratados, sendo clinicamente benéfico no tratamento das lesões experimentais. $O$ tratamento não minimiza de forma significativa o grau de inflamação articular, observada pelas análises do líquido sinovial e pela concentração de PGE2 no líquido sinovial. Os animais tratados demonstram melhor aspecto histopatológico e histoquímico, com a morfologia mais próxima à cartilagem normal, quando comparados aos do grupo-controle. O PRP foi benéfico e eficaz no tratamento de lesões condrais induzidas. A correta utilização e objetivos definidos tornam essa terapia promissora no tratamento de lesões articulares nos equinos.

\section{AGRADECIMENTOS}

Apoio financeiro da Fundação de Amparo à Pesquisa do Estado de São Paulo - FAPESP.

\section{REFERÊNCIAS}

BERTONE, A.L.; PALMER, J.L; JONES, J. Synovial fluid cytokines and eicosanoids as markers of joint disease in horse. Vet. Surg., v.30, p.528-538, 2001.

CARMONA, J. U.; LOPEZ, C.; GIRALDO, C. E. Uso de concentrados autólogos de plaquetas como terapia regenerativa de enfermedades crónicas del aparato musculoesquelético equino. Arch Med Vet, v.43, p.1-10, 2011.

CARMONA, J.U.; LOPEZ, C.; PRADES, M. Uso de concentrados autólogos obtenidos mediante El método del tubo como tratamiento de artropatías em caballos. Arch. Med. Vet., v.41, p.175-179, 2009.

CARTER, C.A.; JOLLY, D.G.; WORDEN, C.E. et al. Platelet-rich plasma gel promotes differentiation and regeneration during equine wound healing. Exp. Mol. Pathol. v.74, p.244255, 2003.

DE GRAUW, J.C.; VAN DE LEST, C.H.A.; VAN WEEREN, R. et al. Arthrogenic lameness of the fetlock: synovial fluid markers of inflammation and cartilage turnover in relation to clinical joint pain. Equine Vet. J., v.38, p.305311, 2006.
EL-SHARKAWY, H.; KANTARCI, A.; DEADY, J. et al. Platelet-rich plasma: growth factors and pro- and anti-inflammatory properties. $J$. Periodontol., v.78, p.661-669, 2007.

EVERTS, P.A.M.; KNAPE, J.T.A.; WEIBRICH, G. et al. Platelet rich plasma and platelet gel, A review. J. Extra Corpor. Techn., v.38, p.174187, 2006.

FORTIER, L.; POTTER H.G.; RICKEY, E.J. et al. Concentrated bone marrow aspirate improves full-thickness cartilage repair compared with microfracture in equine model. J. Bone Jt. Surg., v.92, p.1927-1937, 2010.

FOSTER, T.E.; PUSKAS, B.L.; MANDELBAUM, B.R. et al. Platelet-Rich Plasma from basic science to clinical applications. Am. J. Sports Med., v.37, p.2259-2272, 2009.

GAISSMAIER, C.; KOH, J.L.; WEISE, K. Growth and differentiation factors for cartilage healing and repair. Injury Int. J. Care Injured. v.39, p.88-96, 2008.

JAIN, N.J. Essentials of Veterinary Hematology. Philadelphia: Lea \& Febiger, 1993. 417p.

LOPEZ-VIDRIERO, E.; GOULDING, K.A.; SIMON, D.A. et al. The use of platelet-rich plasma in arthroscopy and sports medicine: optimizing the healing environment. J. Arthrosc. Relat. Surg., v.26, p.269-278, 2010.

MAIA, L. Plasma rico em plaquetas no tratamento de tendinite em equinos: avaliação clínica, ultrasonográfica e histopatológica. 2008. 78f. Dissertação (Mestrado) - Centro de Ciências Biológicas e da Saúde, Universidade Federal de Viçosa, Viçosa, MG.

MARX, R.E.; CARLSON, E.R.; EISCHTAEDT, R.M. et al. Platelet-rich plasma: growth factor enhancement for bone grafts. Oral Surgery, Oral Medicine, Oral Pathology, Oral Radiology, and Endodontology, v.85, p.638-646, 1998.

McCARREL, T.; FORTIER, L. Temporal Growth Factor Release from Platelet-Rich Plasma, Trehalose Lyophilized Platelets, and Bone Marrow Aspirate and Their Effect of Tendon and Ligament Gene Expression. $J$. Orthopaedic Res., v.27, p.1033-1042, 2009.

McILWRAITH, C.W. Diagnostic and surgical arthroscopy in the horse. 3.ed. Mosby-Elsevier, 2005a. 479p. 
McILWRAITH, C.W. From arthroscopy to gene therapy - 30 years of looking in joints. In: AMERICAN ASSOCIATION OF EQUINE PRACTITIONERS ANNUAL CONVENTION, v.51, Colorado. Proceedings ... Colorado, 2005b.

McILWRAITH, C.W.; FRISBIE, D.D.; KISIDAY, J.D. et al. Use of bone marrow-derived cultureexpanded mesenchymal stem cells to augment healing of chondral defects treated with microfracture. In: ANNUAL CONVENTION OF THE AAEP - Baltimore, MD, Proceedings... Baltimore, 2010. v.56, p.27-28.

MILANO, G.; SANNA PASSINO, E.; DERIU, L. et al. The effect of platelet rich plasma combined with microfractures on the treatment of chondral defects: an experimental study in a sheep model. Osteoarthritis and Cartilage, v.18, p.971-980, 2010.

POZZOBON, R.; BRASS, K.E.; FIGHERA, R.A. et al. Características físico-químicas e citológicas do líquido sinovial de pôneis com modelo de sinovite induzida. Cienc. Anim. Bras., v.10, p.1303-1309, 2009.

RAHEJA, L.F.; GALUPPO, L.D.; BOWERSLEPORE, J. et al. Treatment of Bilateral Medial Femoral Condyle Articular Cartilage Fissures in a Horse Using Bone Marrow-Derived Multipotent Mesenchymal Stromal Cells. J. Equine Vet. Sci., v.31, p.147-154, 2011.

ROUSSY, Y.; DUCHESNE, M.B.; GAGNON, G. Activation of human platelet-rich plasmas: effect on growth factors release, cell division and in vivo bone formation. Clin. Oral Impl. Res., v.18, p.639-648, 2007.
SCHLUETER, A.E.; ORTH, M.W. Equine osteoarthritis: a brief review of the disease and its causes. Equine Comp. Exerc. Physiol., v.1, p.221-231, 2004.

STASHAK, T.D. Claudicação em equinos. 5.ed. São Paulo: Roca, 2006. 1093p.

STEEL, C.M. Equine synovial fluid analysis. Vet. Clin. Equine, v.24, p.437-454, 2008.

SUTTON, S.; CLUTTERBUCK, A.; HARRIS, P.; et al. The contribution of the synovium, synovial derived inflammatory cytokines and neuropeptides to the pathogenesis of osteoarthritis. Vet. J., v.179, p.10-24, 2009.

VENDRAMIN, F.S.; FRANCO, D.; NOGUEIRA, C.M. et al. Plasma rico em plaquetas e fatores de crescimento: técnica de preparo e utilização em cirurgia plástica. Rev. Col. Bras. Cir., v.33, p.2428, 2006.

VINATIER, C.; MRUGALA, D.; JORGENSEN, C. et al. Cartilage engineering: a crucial combination of cells, biomaterials and biofactors. Trends in Biotechnol., v.27, p.307-314, 2009.

WILKE, M.M.; NYDAM, D.V.; NIXON, A.J. Enhanced early Chondrogenesis in articular defect following arthroscopic mesenchymal stem cell implantation in a equine model. J. Orthop. Res., v.25, p.914-925, 2007. 